\title{
Hybrid Artificial Intelligent Approach for Determination of Water Saturation using Archie's Formula in Carbonate Reservoirs
}

\section{Hamada $\mathrm{GM}^{1 *}$, Al-Gathe $\mathrm{AA}^{2}$ and Al-Khudafi $\mathrm{AM}^{2}$}

${ }^{1}$ Petroleum Engineering Department, Future University, Egypt

${ }^{2}$ Petroleum Engineering Department, Hadhramout University, Yemen

\begin{abstract}
The challenge to determine the accurate water saturation is still faced Petroleum Engineering. The difficulty of this problem will be increase if we deal with carbonate rocks. There are some available techniques used to determine the water saturation. However, the accuracy of those techniques has become unable to find the best results. Several available techniques have been used to estimate water saturation such as conventional, CAPE $(a, m, n)$, CAPE (1, $\mathrm{m}, \mathrm{n}$ ) and 3D methods. Currently, the achievements of Artificial Intelligent (AI) techniques alone open the door to use the hybrid system such as (PSONN).

In this model, the Particle Swarm Optimization (PSO) technique is employed to search for optimal connection weighs and thresholds for the neural networks (NN), then the back-propagation learning rule and training algorithm is used to adjust the final weights.

A total of about 383 data points obtained from the laboratory measurements of electrical properties from carbonate core plugs of Middle East reservoir were used for the implementation of the proposed technique.

Statistical analysis and comparative study show that the performance of PSONN model is the best one with lower root mean square error (0.092) and higher accuracy of correlation coefficient $(0.95)$ than those obtained with previous methods. Results showed that the new hybrid PSONN model outperforms some available methods and overcome the weakness if we use Al alone. From error analysis, it is found that CAPE and 3-D and PSONN methods ensure minimum error of water saturation values.
\end{abstract}

Keywords: Water saturation; 3D technique; CAPE; Conventional technique; Carbonate reservoir; Artificial Intelligence

\section{Nomenclature}

a: Tortuosity factor

$\mathrm{m}$ : Cementation factor

n: Saturation exponent

Sw: Water saturation, fraction

Rt: Resistivity of rock, $\Omega . \mathrm{m}$

Rw: Resistivity of brine,- $\Omega . m$

Ro: Resistivity of rock with $\mathrm{Sw}=1.0, \Omega . \mathrm{m}$

Ir: Resistivity index

F: Formation resistivity factor

$\varphi$ : Formation porosity, fraction

Ea: Average Absolute Percent Relative Error

Emin/Emax: Minimum/Maximum Absolute Error

S: Standard deviation

Erms: the root mean square error

$\mathrm{R}$ : the correlation coefficient

\section{Introduction}

An accurate determination of initial oil in place in the early life of reservoirs or an evaluation of a developed reservoir is required to well estimate the water saturation. The accuracy of water saturation value for given reservoir conditions depends on the accuracy of Archie parameters $\mathrm{a}, \mathrm{m}$ and $\mathrm{n}$. Uncertainty in these coefficients causes many errors in saturation evaluation especially in the carbonate reservoir. Archie equations are the basic relations for evaluating rock saturation. The coefficients of these equations are determined by laboratory experiments [1].

Pirson established a scale indicating the degree of cementation using $\mathrm{m}$ values Amin observed the Archie factor (m) varies over a wide range in the carbonate reservoirs of the Middle East [2,3]. Focke and Munn found out that cementation parameter is a function of the rock lithology and it varies significantly in carbonate rocks [4]. Borai noted that Archie's relationship with cementation factor of $m=2$ is applicable for formations with medium to high porosity [5]. Wang developed an empirical correlation for carbonate rocks between formation factor and porosity, permeability and porosity, permeability and residual water saturation, saturation exponent and residual water saturation, sonic velocities porosity and formation factor [6]. Harris obtained a relationship between the porosity and the cementation exponent for a particular zone [7]. Talia performed a series of experiments in order to derive the correct form of the Archie's Equation that can

*Corresponding author: Hamada GM, Petroleum Engineering Department, Faculty of Engineering and Technology, Future University, Egypt, Tel: 00201003749609; E-mail: gharib.hamada@fue.edu.eg

Receive September 23, 2015; Accepted November 03, 2015; Published November 13, 2015

Citation: Hamada GM, Al-Gathe AA, Al-Khudafi AM (2015) Hybrid Artificial Intelligent Approach for Determination of Water Saturation using Archie's Formula in Carbonate Reservoirs. J Pet Environ Biotechnol 6: 250. doi:10.4172/21577463.1000250

Copyright: (c) 2015 Hamada GM et al. This is an open-access article distributed under the terms of the Creative Commons Attribution License, which permits unrestricted use, distribution, and reproduction in any medium, provided the original author and source are credited. 
be applied to carbonate rocks [8]. Tabib M Emadi explained a new method of achieving variable $\mathrm{m}$ using the most effective reservoir parameters for any arbitrary interval of reservoir [9]. Fleury presented an extensive laboratory study to determine initial water saturation as well as remaining oil in water flooded regions in a carbonate field [10]. Knackstedt presented results of a 3D pore scale study of the resistivity properties in twelve model and reservoir core samples. He also noted that the laminated sand exhibit strong anisotropy and the complex carbonate systems exhibit values of $\mathrm{n}$ that vary strongly with water saturation [11]. Han studied the influence of the pore space structure on resistivity index curves of sandstones and carbonates. They present a new method for measuring the resistivity index (RI) curve in air-brine system in drainage and imbibition [12]. Dernaika estimated the initial water saturation by using the RI-Sw curves in drainage [13]. Archie proposed the electrical resistivity of sandy rocks was related to porosity as follows:

$$
F=\varnothing^{-m}
$$

Where:

$$
F=R_{o} / R_{w}
$$

Ro is the resistivity of the completely saturated formation, $\mathrm{Rw}$ is the resistivity of the fluid (brine resistivity), $\mathrm{F}$ is formation factor and $\mathrm{m}$ is a cementation factor. Archie noticed $\mathrm{m}$ increased with the degree of cementation factor of sand samples, being the highest for hard sands and the lowest for loose sands. A more general relationship was developed by Winsauer:

$$
F=a \varnothing^{-m}
$$

In 1942, Archie's equation is developed based on empirical relationship between the three following parameters: water saturation Sw, porosity, $\varnothing$, and rock resistivity, Rt.

$$
S_{w}^{n}=a R_{w} / \varnothing^{m} R_{t}=R_{o} / R_{t}=1 / I_{r}
$$

where $\mathrm{Rt}$ is the resistivity of the partially saturated formation, 'Sw' is the water saturation, ' $a$ ' is the tortuosity factor and ' $n$ ' is the saturation exponent, typically taken to be 2.0 , on the basis of laboratory studies of core.

Cementation exponent varies constantly which has a significant effect on the computation of water saturation using resistivity logs. These equations are not still used for non-Archie reservoirs (carbonate reservoir) because data-driven perception of reservoir complexity often is too simplistic $[14,15]$.

This paper presents the results of the application of four techniques to determine Archie's parameters: (1) three-dimensional regression (3D) technique, which is based on the analytical expression of three dimension plot of Rt/Rw versus Sw and $\emptyset$, equation (2) core Archie's parameters estimate (CAPE) and equation (3) conventional technique, equation (4) Particle swarm optimization with neural network (PSONN). Uncertainty analyses have been tested for all Archie's parameters determination techniques and the relevant impact on the water saturation values.

\section{Literature Review}

\section{Determination of Archie equation parameter}

Water saturation is not still estimated by Archie's Equation because formation parameters $(a, m, n)$ are functions of changes of rocks properties. Therefore, the several techniques are proposed such as
Conventional method, Core Archie-Parameter Estimation (CAPE), (a, $\mathrm{m}, \mathrm{n}$ ) or CAPE $(1, \mathrm{~m}, \mathrm{n}), 3 \mathrm{D}$ method and Hybrid PSONN Technique.

Conventional method: Archie's equation parameters are estimated directly from electrical measurements. Equation (3) is used to determine constant, a as the intercept and cementation factor, $\mathrm{m}$ as slope by plotting ' $F$ ' vs. $\varnothing$. The coefficient, $\mathrm{n}$ is calculated based on the equation (4) by plotting ' $\mathrm{S}_{\mathrm{w}}$ ' vs 'Ir'. Figure 1 shows the saturation exponent values for 29 core samples. Figure 2 illustrates $F$ vs $\emptyset$ for core samples; average ' $m$ ' equals to 1.87 and the coefficient, a equals to 1.12 . This separation for estimation Archie's coefficients is not physically correct, thereby, it induces an error in the value of water saturation using equation 4 .

Core Archie-parameter Estimation (CAPE): Maute developed a mathematical method to estimate Archie's parameters $\mathbf{m}, \mathbf{n}$ and optionally a from standard resistivity measurements on core samples. The main idea of this method is to calculate the Archie's parameters by minimizing the mean square error between the actual and the predicted water saturations by using Archie's Equation. Maute found that the results of the CAPE method in calculated water saturation agree well with the actual core data and better than the conventional method results [16].

3D-method: Although the CAPE method is a good to estimate Archie parameters ( $\mathrm{a}, \mathrm{m}$, and $\mathrm{n}$ ) but the CAPE method has a difficulty to apply their complex mathematical equations. Therefore, Hamada [17] proposed 3D method to determine Archie's Equation parameters a, $\mathrm{m}$ and $\mathrm{n}$ based on the water saturation, porosity and formation resistivity measurements on core samples. The $3 \mathrm{D}$ method also overcomes the uncertainty problems due to the separate use of porosity, formation resistivity factor and water saturation equations to get the Archie's Equation parameters $a, m$ and $n$.

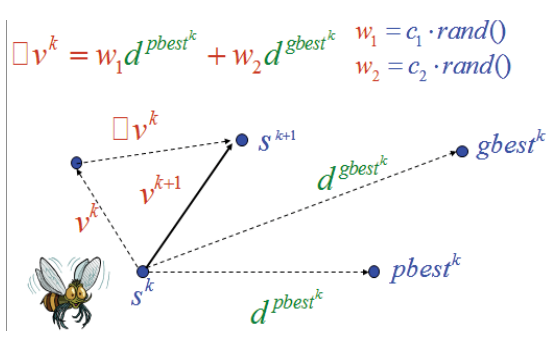

Figure 1: shows particle flying model.

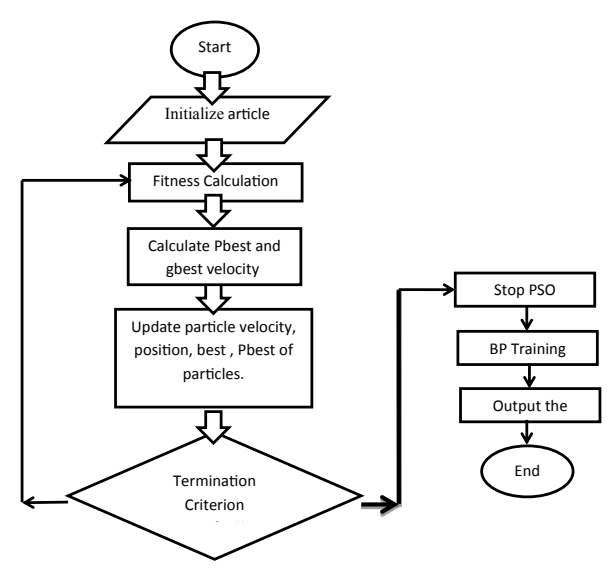

Figure 2: The basic PSO procedure. 
It must be highlighted that the above mentioned methods are not the main objective of this work. Therefore a detail methodology of these methods is not given in this research. Rather, we use Hybrid PSONN Technique to predict water saturation and compare the results with those obtained by Hamada using the above methods for the same electrical measurements [13].

Hybrid artificial intelligent: The achievements of the Artificial Intelligent $(\mathrm{AI})$ techniques alone open the door to use the hybrid system. This research focuses on the use of predictive capabilities of Particle Swarm Optimization with capabilities learning of Neural Network (PSONN) combination [18]. Jing-Ru Zhang introduced a hybrid algorithm combining particle swarm optimization (PSO) algorithm with back-propagation ( $\mathrm{NN}$ ) algorithm to train the weights of feedforward neural network (FNN) [19]. Al-Mudhafer and Abbas developed hybrid System of Genetic Algorithm and Fuzzy Logic as Optimization Techniques for determining the optimal future reservoir performance regarding to infill drilling [20]. Valipour developed Auto Regressive Moving Average (ARMA) and Auto Regressive Integrated Moving Average (ARIMA) models for forecasting the inflow of Dez dam reservoir and comparing the results with the static and dynamic artificial neural networks [21].

Diptam Dutta proposed Particle Swarm Optimization (PSO) to adapt the network weights as a mechanism to improve the performance of Artificial Neural Network (ANN) in classification of IRIS dataset. Mohammad Ali developed a novel and rigorous methods based on two different types of intelligent approaches including the artificial neural network (ANN) linked to the particle swarm optimization (PSO) tool to precisely forecast the productivity of horizontal wells under pseudo-steady-state conditions [22]. Hossein Sayyad proposed hybrid neural particle swarm optimization algorithm for prediction of gas-oil minimum miscibility pressure (MMP) to improve enhance oil recovery [23]. Das applied ANN trained with PSO for the problem of channel equalization. They employed PSO to optimize the number of layers, the type of transfer functions, input and hidden neurons etc.

Particle swarm optimization: Particle swarm optimization (PSO) is a robust stochastic optimization technique based on the movement and intelligence of swarms [24]. It applies to look for the optimal solution by simulating the movement and flocking of birds.

The PSO starts by initializing a flock of birds randomly over the searching space. Each bird called as particle. Particles fly with a particular velocity and try to find the global best position (gbest) after some iteration. At each iteration, each particle is treated as a point in a $\mathrm{N}$-dimensional space which adjusts its velocity according to its momentum and the influence of its best position (pbest) as well as the best position of its neighbors (gbest), and then compute a new position that the particle is to fly to. The basic concept of PSO lies in accelerating each particle toward its pbest and the gbest locations, with a random weighted acceleration $(w)$ at each time.

Figure 1 describes the particle flying model. For more details about particle swarm optimization model and description is discussed in Eberhart and Kennedy [24,25].

After finding the two best values, the particle updates its velocity and positions with following equation (5) and (6).

$$
\begin{aligned}
& \mathrm{V}_{\mathrm{i}}^{(\mathrm{k}+1)} \quad \mathrm{w} * \mathrm{~V}_{\mathrm{i}}^{(\mathrm{k})} \quad \mathrm{C}_{1} * \alpha *\left(\text { pbest }_{\mathrm{i}} \quad \mathrm{S}_{\mathrm{i}}^{(\mathrm{k})}\right) \quad \mathrm{C}_{2} * \beta *\left(\text { gbest }_{\mathrm{i}} \mathrm{S}_{\mathrm{i}}^{(\mathrm{k})}\right) \cdots \cdots \\
& \mathrm{S}_{\mathrm{i}}^{(\mathrm{k}+1)}=\mathrm{S}_{\mathrm{i}}^{(\mathrm{k})}+\mathrm{V}_{\mathrm{i}}^{(\mathrm{k}+1)}
\end{aligned}
$$

In the above equation, the term $\hat{a}^{*}\left(\right.$ gbest $\left._{\mathrm{i}}-\mathrm{S}_{\mathrm{i}}^{(\mathrm{k})}\right)+\mathrm{C}_{2}$ is called particle memory influence, the term $\hat{a}^{*}\left(\right.$ gbest $\left._{i}-S_{i}^{(k)}\right)+C_{2}$ is called swarm influence, $\left(V_{i}^{(k)}\right.$ and $\left.S_{i}^{(k)}\right)$ which are the velocity and position of ith particle at iteration ' $\mathrm{k}$ ', the acceleration constants $\mathrm{C} 1$ and $\mathrm{C} 2$ pull each particle towards pbest and gbest positions, $\alpha, \beta$ are random values and inertia weight ' $\omega$ ' provides a balance between global and local explorations.

Each particle tries to modify its position using the following information:

The current positions $\mathrm{S}_{\mathrm{i}}^{(\mathrm{k})}$,

The current velocities $\mathrm{V}_{\mathrm{i}}^{(\mathrm{k})}$,

The distance between the current position and pbest,

The distance between the current position and the gbest.

\section{Hybrid PSONN Model Development}

The PSO-NN is an optimization algorithm combining the Particle Swarm optimization (PSO) with the back-propagation Neural Network $(\mathrm{NN})$. PSO algorithm was shown the convergence rapidly during the initial stages of a global search, but around global optimum, the search process will become very slow. On the other hand, Back Propagation Neural Network (BNN) has a strong ability to find the local optimistic result, but its ability to find the global optimistic result is weak Therefore, integrating PSO and NN can achieve faster convergent speed around global optimum, and at the same time, the convergent accuracy can be higher. Moreover, combining PSO with Neural Network can overcome the weakness of each technique. The PSONN algorithm combines the features of PSO with back-propagation neural network in order to improve the Neural Network [26].

The learning process of PSONN has two stages: Firstly PSO is applied to search for approximate optimal connection weights and thresholds for the network, then the back-propagation learning rule and training algorithm is used to adjust the final weights.

Figure 2 shows the following learning process steps of the PSONN:

- The Neural Network weights and biases are initialized as randomly particle to a certain position in the problem space.

- The number of dimensions in the problem space is equal to the number of weights and thresholds there are to optimize.

- This operation is completed by applying a BP algorithm on the PSO established initial connection weights and thresholds.

- For each particle, calculate particle velocity according equation (6) and update particle position according equation (7).

The PSONN algorithm combines the features of PSO with backpropagation neural network in order to improve the Neural Network.

In this research, the neural network parameters were optimized by the PSO algorithm and the adopted feed forward neural network has two layers. The optimal first hidden layer used (tansig) as a transfer function whereas the other hidden layer used (purelin) as a transfer function.

The position of each particle in PSONN represents a set of weight for current iteration. The dimension of each particle is the number of weights connected with the network. The learning error of this network is calculated using Root Mean Squared Error (RMSE). The particle will move within the weight space in order to minimize learning error. 
Citation: Hamada GM, Al-Gathe AA, Al-Khudafi AM (2015) Hybrid Artificial Intelligent Approach for Determination of Water Saturation using Archie's Formula in Carbonate Reservoirs. J Pet Environ Biotechnol 6: 250. doi:10.4172/2157-7463.1000250

\section{Development of fitness function}

The selection of fitness function depends on the research goals. Root Mean Squared Error (RMSE) is used here as a fitness function. Optimization fitness function is important to ensure that RMSE or learning error is getting lesser with the increase of number iterations. The feed-forward neural network with two layered structures was developed (Figure 3).

\section{Data Description}

A total of 44 plug samples were received from three wells. Seventeen core samples are studied from well A, fifteen core samples from well B, and twelve core samples from well C. These core samples had different ranges of porosity and permeability. These samples are a carbonate core samples (limestone and dolomite). Table 1 describes the total data points.

\section{Statistical Error Analysis}

Statistical and graphical error analyses were used to check the accuracy and performance of those developed techniques in this study. The accuracy of the correlation relative to the actual value is determined by using various statistical means. The criteria used in this study were average percent relative error, average absolute percent relative error (AAPRE) and minimum/maximum absolute percent relative error, the correlation coefficient (CC), and the root mean square error (RMSE).

\section{Result and Discussion}

The optimal configuration for PSONN network was found to be as follow:
a) Number of Hidden Layers $=2$.
b) Number of Hidden Neurons $=25$.
c) Number of Max Iteration $=100$.
d) Cognitive Parameter (c1), value of 0.5.
e) Social Parameter (c2), value of 1.0.
f) No. of population (No of bird) 60 number of particles
g) No. of generations 500 .
h) Inertia weight $(w), 0.7$.
i) Max. velocity,
j) No of dimension 126 .

Number of dimension in PSONN is referring to number of weight and bias that is based on input data and PSONN architecture. PSONN dimension is calculated using Equation (7).

Dimension $=\left(\right.$ input ${ }^{\star}$ hidden input $)+\left(\right.$ hidden ${ }^{\star}$ output hidden $)$

+ hidden $_{\text {bias }}$ +output $_{\text {bia }}$

The PSONN technique was used in this study to estimate water saturation "Sw" based on the resistivity measurement (Rt, Rw and $\phi$ ) as input of the model. In order to validate PSONN technique results, we have used the statistical error analysis criteria for evaluation the PSONN performance; Maximum Absolute Error $\left(\mathrm{E}_{\max }\right)$, Minimum Absolute Error $\left(\mathrm{E}_{\min }\right)$, Average Error $\left(\mathrm{E}_{\mathrm{a}}\right)$, Root mean square error $\left(\mathrm{E}_{\mathrm{rms}}\right)$, standard division Error $(\mathrm{S})$ and Correlation Coefficient $(\mathrm{R})$.

Now, the conventional, CAPE, and 3D techniques are applied by considering field examples of effectively carbonate rock. Figures 4 and 5 illustrate the calculated Archie's parameters using conventional methods. Table 2 summarized the typical results of Archie's parameters values from the conventional method, the CAPE method, and the $3 \mathrm{D}$ method. Note that for CAPE method, cases where a, is fixed at unity and variable are given.

In addition the Archie's parameters ( $m, n$ and a) values of each technique are used to calculate water saturation. The predicted water saturation values results from five techniques are compared with measured water saturation values. The statistical error analysis is used to evaluate those techniques regarding to water saturation values and the results summarized in Table 3. Figures 6 and 7 show the average error, the root mean square error, standard deviation, and finally the correlation coefficient error consequently.

The results obtained by PSONN for water saturation showed more improvement than the other techniques. The PSONN technique achieved the best one with highest correlation coefficient equal to 0.95

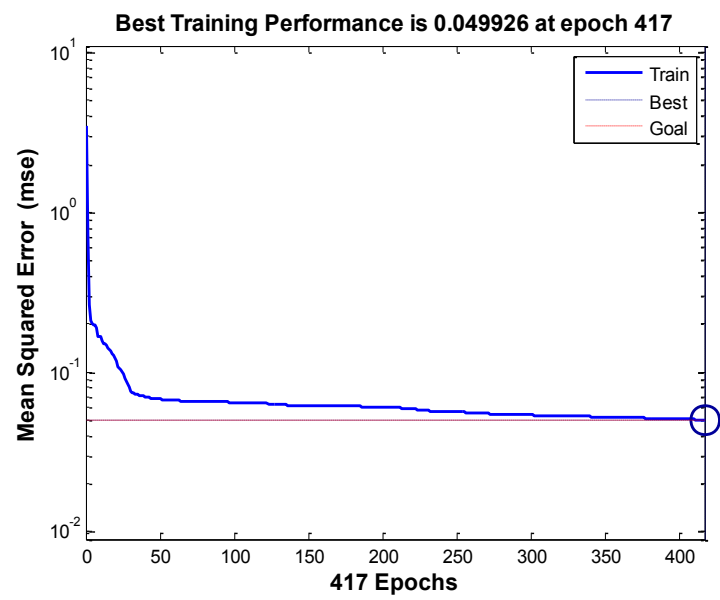

Figure 3: Training performance of PSONN

\begin{tabular}{|c|c|c|}
\hline Well Name & No. of Plugs & No. of data points \\
\hline Well\#1 & 17 & 153 \\
\hline Well\#2 & 15 & 126 \\
\hline Well\#3 & 12 & 103 \\
\hline Total & 44 & 383 \\
\hline
\end{tabular}

Table 1: Data description.

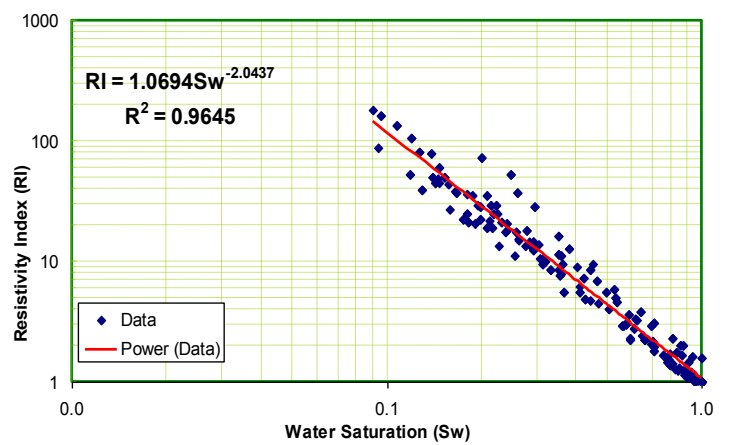

Figure 4: Resistivity vs. water saturation for 29 core samples. 
Citation: Hamada GM, Al-Gathe AA, Al-Khudafi AM (2015) Hybrid Artificial Intelligent Approach for Determination of Water Saturation using Archie's Formula in Carbonate Reservoirs. J Pet Environ Biotechnol 6: 250. doi:10.4172/2157-7463.1000250

Page 5 of 7

\begin{tabular}{|c|c|c|c|}
\hline Method & $\mathbf{a}$ & $\mathbf{m}$ & $\mathbf{n}$ \\
\hline Conventional Method & 1.12 & 1.87 & 2.04 \\
\hline CAPE $(1, \mathrm{~m}, \mathrm{n})$ Method & 1.00 & 1.52 & 1.92 \\
\hline CAPE $(\mathrm{a}, \mathrm{m}, \mathrm{n})$ Method & 0.23 & 2.15 & 2.87 \\
\hline 3-D.Method & 0.28 & 2.34 & 2.12 \\
\hline
\end{tabular}

Table 2: Archie's parameters values from four techniques.

\begin{tabular}{|l|c|c|c|c|c|c|}
\hline \multirow{2}{*}{ Methods } & \multicolumn{3}{|c|}{ Absolute Error } & \multirow{2}{*}{$\mathbf{E}_{\mathbf{r m s}}$} & $\mathbf{S}$ & $\mathbf{R}$ \\
\cline { 2 - 7 } & $\mathbf{E}_{\mathbf{a}}$ & $\mathbf{E}_{\min }$ & $\mathbf{E}_{\max }$ & & & \\
\hline Conventional Method & 0.206 & 0.004 & 1.09 & 0.31 & 0.23 & 0.90 \\
\hline CAPE $(1, \mathrm{~m}, \mathrm{n})$ Method & 0.125 & 0.001 & 0.38 & 0.16 & 0.10 & 0.90 \\
\hline CAPE $(\mathrm{a}, \mathrm{m}, \mathrm{n})$ Method & 0.095 & 0.001 & 0.33 & 0.12 & 0.08 & 0.92 \\
\hline PSONN Technique & 0.064 & 0.0001 & 0.34 & 0.09 & 0.067 & 0.95 \\
\hline 3-D.Method & 0.102 & 0.002 & 0.51 & 0.14 & 0.10 & 0.91 \\
\hline
\end{tabular}

Table 3: Error analysis of Archie's parameters determination techniques.

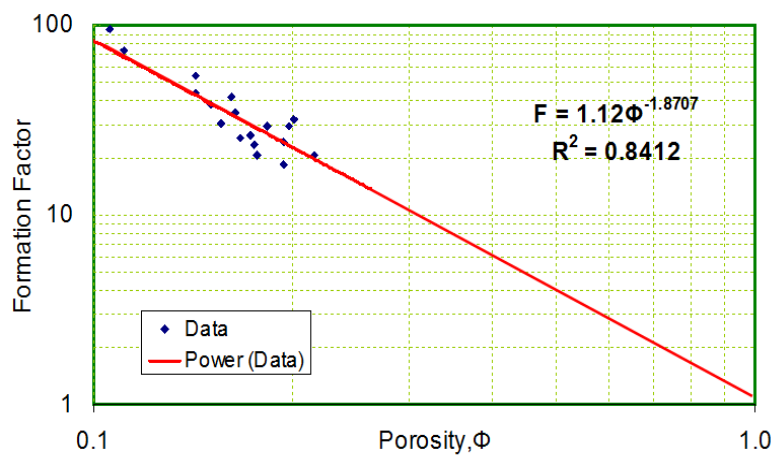

Figure 5: Formation factor vs. porosity for 29 core samples.

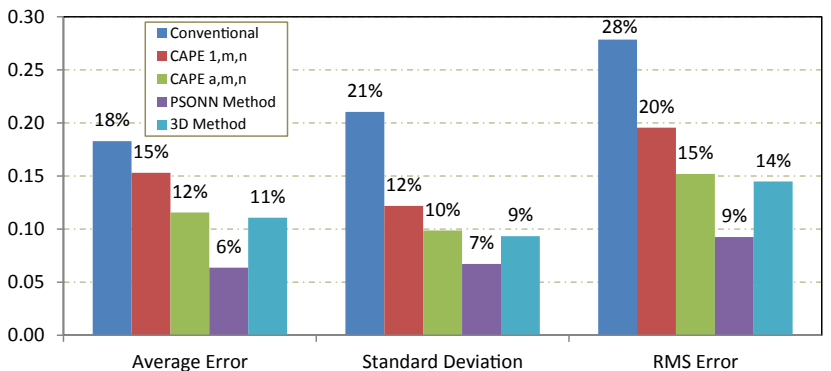

Figure 6a: The average error, RMS error and standard deviation between the four techniques.

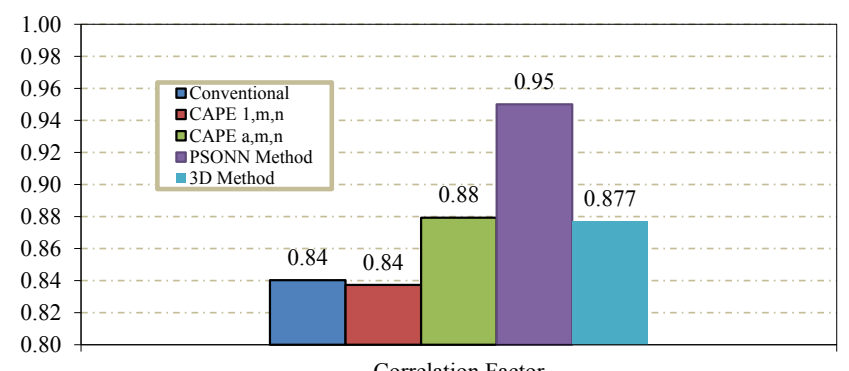

Figure 6b: The average error, RMS error and standard deviation between the four techniques. and lowest root mean square error equal to 0.092 . Figure 8 shows that a comparison between measured and predicted water saturation values as well as their relative errors comparison shows the same trend. This comparison shows the good agreement between the PSONN method and actual water saturation values.

It can be concluded that PSONN technique has superiority for estimating water saturation from resistivity measurements.

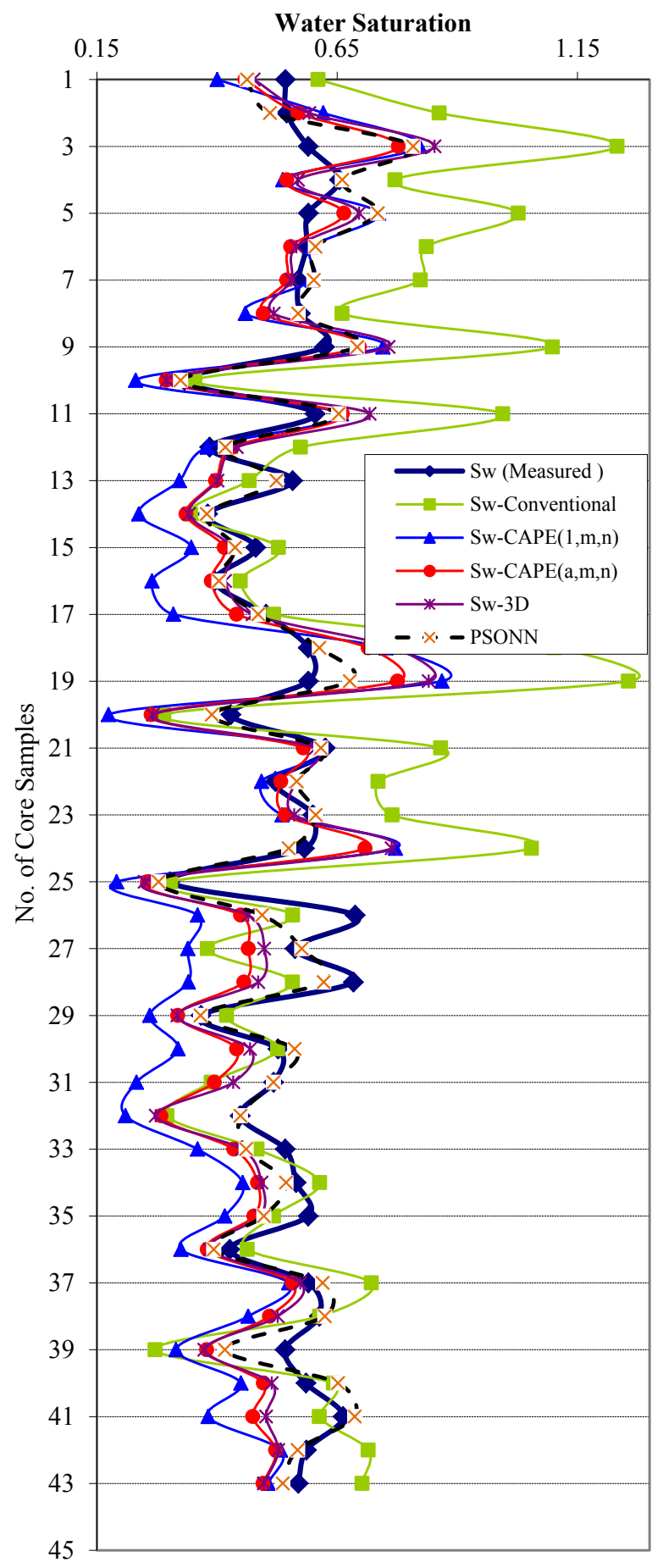

Figure 7: The correlation coefficients values for the different techniques. 
Citation: Hamada GM, Al-Gathe AA, Al-Khudafi AM (2015) Hybrid Artificial Intelligent Approach for Determination of Water Saturation using Archie's Formula in Carbonate Reservoirs. J Pet Environ Biotechnol 6: 250. doi:10.4172/2157-7463.1000250

Page 6 of 7

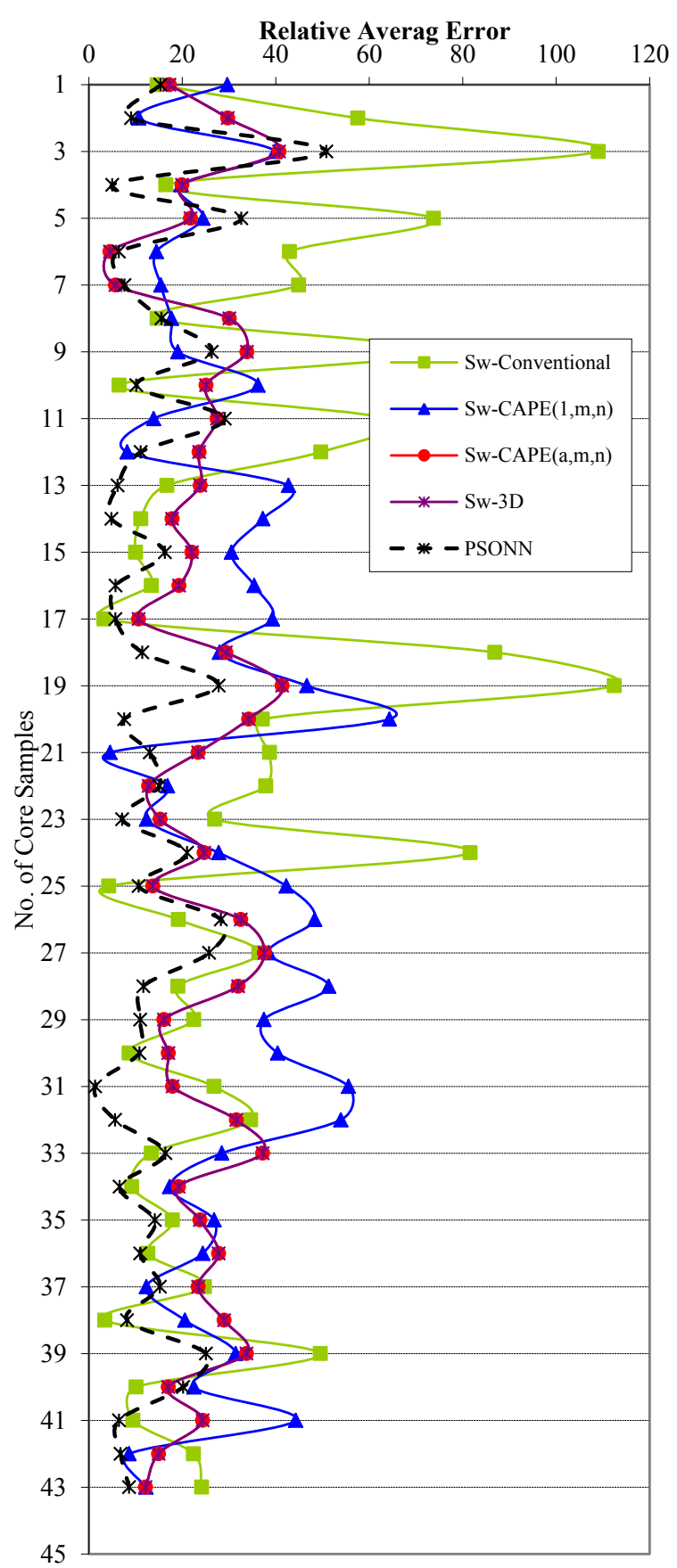

Figure 8: A) Comparison between measured and calculated water saturation of five techniques, and B) Comparison between their Relative errors of the five techniques.

\section{Validation}

In order to examine the reliability of these techniques, the statistical error analyses were used to validate these techniques. Figure 6 through Figure 8 show an excellent agreement between both measured and predicted water saturation values using PSONN technique. Table 3 summarizes the results of statistical error analysis of these techniques.

\section{Conclusions}

From the analysis of the different determination techniques of Archie's parameters on carbonate reservoirs rock samples, the following conclusion points can be drawn.

1. Intelligent techniques are powerful tools which overcome incompleteness, imprecise and uncertainty existent in reservoir parameters.

2. The hybrid models showed superior performance with the highest correlation coefficients, and lowest root mean square errors.

3. Hybrid optimization method is faster and more accurate than any artificial intelligent algorithm alone.

4. Conventional technique optimizes the two functions $\mathrm{F}$ vs. $\phi$ and Rt vs. Sw rather than water saturation values in the determination of Archie's parameters.

5. Unlike the conventional method which ignores the values of $\mathrm{Sw}<1.0$ in the determination of a and $\mathrm{m}$, the PSONN, 3-D and CAPE use all the data of Sw points.

6. CAPE and 3-D give values of Archie's parameters that minimize the error in the desired quantity of water saturation.

7. Error analysis of water saturation values increases on going from CAPE to 3-D and conventional techniques.

8. Standard deviation and correlation factor showed that PSONN is the best one while conventional is the worst technique.

\section{References}

1. Pirson SJ (1958) "Factors Which Affect True Formation Resistivity," Oil and Gas J.

2. Amin AT, Watfa M, Awad MA (1987) "Accurate Estimation of Water Saturation in Complex Carbonate Reservoirs," SPE 15714, Middle East Oil Show, Manama, Bahrain

3. Focke JW, Munn D (1985) "Cementation Exponents in Middle Eastern Carbonate Reservoirs". SPE\#13735 Middle East Oil Technical Conference and Exhibition, Bahrain.

4. Borai AM (1987) "A New correlation for the cementation factor in low-porosity Carbonates," SPE Formation Evaluation 2: 495-499.

5. Wang Z, Hirsche WK, Sedgwick GE (1991) "Electrical and Petrophysical Properties of Carbonate Rocks," SPE\# 22661, Dallas.

6. Harris JC, Saha GB, Asquith GB, Arnold MD (1992) "Determination of Archie Parameters $\mathrm{m}$ and $\mathrm{n}$ by Combining Core Analysis with Dielectric Logs," SCA Conference Paper Number 9205, Texas, USA.

7. Talia SA, Soran T, Vaziri HH, Islam MR (2001) "In-Depth Investigation of the Validity of the Archie Equation in Carbonate Rocks," SPE 67204, Production and Operations Symposium, Oklahoma, USA.

8. Tabib M, Emadi MA (2003) "Variable Cementation Factor Determination (Empirical Methods)," SPE\# 81485, Bahrain.

9. Fleury M, Efnik M, Kalam MZ (2004) "Evaluation of Water Saturation from Resistivity Carbonate Field from Laboratory to Log". The International Symposium of the Society of Core Analysts, Abu Dhabi.

10. Knackstedt AM, Arns CH, Sheppard AP, Senden TJ, Sok RM, et al. (2007) "Pore Scale Analysis of Electrical Resistivity in Complex Core Materal," Society of Core Analysts, Calgary, Canada.

11. Han M, Fleury M, Levitz P (2007) "Effect of the Pore Structure on Resistivity Index Curves," Society of Core Analysts," Calgary, Canada.

12. Dernaika M, Efnik MS, Koronful MS, Al Mansoori M, Hafez H, et al. (2007) "Case Study for Representative Water Saturation from Laboratory to Logs and the Effect of Pore Geometry on Capillarity," Society of Core Analysts, Calgary, Abu Dhabi. 
Citation: Hamada GM, Al-Gathe AA, Al-Khudafi AM (2015) Hybrid Artificial Intelligent Approach for Determination of Water Saturation using Archie's Formula in Carbonate Reservoirs. J Pet Environ Biotechnol 6: 250. doi:10.4172/2157-7463.1000250

Page 7 of 7

13. Archie GE (1942) "The electrical resistivity log as an aid in determining some reservoir Characteristics," Trans. AIME, 146: 54-62.

14. Morgan WB, Pirson SJ (1964) "The effect of fractional wettability on the Archie saturation exponent," Paper B presented at 5th SPLWAL Annual Technical Conference, Midlands, USA.

15. Hamada GM, Almajed AA, Okasha TM, Algathe AA (2013) “Uncertainty analysis of Archie's parameters determination techniques in carbonate reservoirs". J Petrol Explor Prod Technol 3: 1-10.

16. Maute KE, Lyle WD, Sprunt E (1992) "Improved data- analysis method determines Archie parameters from core data," JPT 103-107.

17. Hamada GM, Al-Awad MN, Al-Sughayer (2002) "Water Saturation Computation from Laboratory, 3-D Regression". Oil \&Gas and Technology Rev, IFP 57: 637 651.

18. Zhang J, Zhanga J, Lokc T, Lyu MR (2007) "A hybrid particle swarm optimization-back-propagation algorithm for feed forward neural network training," Applied Mathematics and Computation 185: 1026-1037.

19. Al-Mudhafer WJ, Abbas M (2012) "Application of a Hybrid System of Genetic Algorithm \&Fuzzy Logic as Optimization Techniques for Improving Oil Recovery in a Sandstone Reservoir in Iraq". SPE149982, SPE Latin America and Caribbean Petroleum Engineering Conference.
20. Valipour M, Banihabib ME, Behbahani SMR (2013) "Comparison of the ARMA ARIMA, and the autoregressive artificial neural network models in forecasting the monthly inflow of Dez dam reservoir". Journal of Hydrology 467: 433-441.

21. Dutta D, Roy A, Choudhury K (2013) "Training Artificial Neural Network using Particle Swarm Optimization Algorithm," International Journal of Advanced Research in Computer Science and Software Engineering, 3: 430-434.

22. Sayyad H, Manshadb AK, Rostami H (2014) "Application of hybrid neura particle swarm optimization algorithm for prediction of MMP". Fuel journal 116 625-633.

23. Das G, Patnaik PK, Padhy SK (2014) "Artificial Neural Network trained by Particle Swarm Optimization for non-linear channel equalization," Expert Systems with Applications 41: 3491-3496.

24. Eberhart R, Kennedy J (1995) A new optimizer using particle swarm theory in Micro Machine and Human Science MHS'95 Proceedings of the Sixth International Symposium on, IEEE.

25. Kennedy WD, Herrick DC, Yao T (2001) "Calculating water saturation in electrically anisotropic media”. Petrophysics 42: 118-136.

26. Ahmadia MA, Soleimanib R, Leec M, Kashiwaod T, Bahadori A (2015) "Determination of oil well production performance using artificial neural network (ANN) linked to the particle swarm optimization (PSO) tool," Petroleum journal by Southwest Petroleum University 1: 118-132. 